\title{
Outdoor training for students in the context of distance education
}

\author{
Aleksandr Prishchepa*, and Olesya Maydibor \\ Don State Technical University, 344010, Rostov-on-Don, Russia
}

\begin{abstract}
The article reveals the main problems of art and pedagogical education in teaching students to paint in the open air practice in the conditions of distance learning. The modern educational environment has put forward new conditions for the methodology of teaching the fine arts using computer technology. Primary data processing on the development of a theoretical and methodological substantiation of the traditional system of teaching painting, existing IT technologies and programs that allow distance learning in different modes, confirm the possibility of using a new direction in artistic pedagogy, which reveals the potential for the implementation of new pedagogical ideas at a high effective level. Modeling a new educational process includes the development of new curricula, not only in the field of traditional education, but also the participation of IT technologies in the adaptation of electronic learning systems to working conditions in the open air, in various modes of transferring audio and video information. Traditional curricula should also be modernized to fit the structure of an e-learning resource. The most successful solution to this educational problem will allow bringing the system of artistic training of students to a new educational level, since will allow remotely conducting classes by leading highly qualified specialists from various regions and countries.
\end{abstract}

\section{Introduction}

The problem of distance learning in art pedagogy in modern education occupies a special place

The peculiarity of painting in the open air at different historical times in the theory and methodology of fine arts was an aspect of the attention of many leading academics, professors, teachers and practice leaders. Traditional forms of teaching painting in the open air have been sufficiently studied and disclosed in various sources. The problems of modeling space, transferring light-air perspective in the conditions of painting in the open air were noted in the studies of O.N. Maidibor. "The student has difficulty with an elementary linear perspective. It will not be possible to transfer knowledge of the linear perspective of the interior to the landscape automatically, and this cements the student's consciousness. He discovers that he is not able to do even the elementary things. " [one]. During the writing of the etude, it is necessary to "make plans", ie. conditionally divide the

\footnotetext{
*Corresponding author: cafdidpi@mail.ru
} 
space into near, middle and far sections. There may be more than three of them, but not less. Each area must be written taking into account the luminosity, transparency and thermal coldness. The emotional coloring of the depicted plot is transformed by the artist through the temperament, expressed in the length of the stroke, the expressive pressure of the pencil, the rhythm of the stroke, saturation, brightness, or vice versa, a dull, dense painting spot. But the actual process of writing and drawing a sketch must be psychologically measured and balanced. The artist must experience all the emotional intensity before starting to work on the image. Psychic reflection should be deposited in the artist's memory and nourish the creative process at the necessary moments, the artist himself at this moment should be focused on solving professional problems, of which there are a great many. To which S.P. Lomova points out in her research. "Novice painters should study nature in all its manifestations, constantly develop and accumulate a stock of observations and ideas about it. It is necessary to comprehensively analyze various phenomena, objects, details, elements of the landscape, both individually and in interaction with surrounding objects, lighting, environment. It is necessary to study the harmony of colors, shapes, details of the surrounding world, write long and short sketches at different times of the year, day and weather conditions, make sketches and sketches, both from individual elements of the landscape, and from "panoramic", "picturesque" views. [2] For a concrete understanding of exactly what tasks constitute the artist's professional interest, one needs to read a lot of special literature and look at analogs, to develop one's own concept of the landscape. According to A.A. Prischepa. "The principle of the concept should determine the most general attitudes aimed at merging the functional-spatial qualities of the environment and the features of its subject saturation. This component can be traced on the example of a complex that represents the essence of the development of a design concept. " [3]

The artist remembers the first emotional reaction from the nature he saw, and after some time, during the period of work on the landscape, he fishes out from his own memory. The principle of pacification and peace is inherent in many types of creativity and craft. Even if we recall the techniques of martial arts, we will find certain parallels. An athlete should not experience any aggression, hatred or love, everything should happen in fusion with nature, the body, heartbeat, brain work, muscles, and many others. Dimension polishes technique. A high level of technology is also required in artistic creation. "When working on a landscape, you can't just "sketch" it. The landscape requires an excited, poetic attitude to reality from the artist. The painter conveys not only the visible "subject plot", the beauty of the landscape, but also the mood that the depicted motive evoked in his soul. " [2]

\section{Materials and methods}

The teaching of painting in the open air of students is reflected in the studies of N.V. Zinchenko, L.A. Zhadanova, O.N. Maidibor and others over the years. The results of these studies are reflected in dissertations, scientific articles, which show diagrams, graphs and tables. The distance form of teaching painting in the open air was carried out in 2019-2020 at the Don State Technical University at the Department of Fine Arts by the heads of the practices K.T. Dagldiyan, S.V. Lukyanov, A.A. Prischepa.

Possession of the technique of painting landscapes, still lifes, portraits in various materials, forms professional qualities.

The process of working with watercolors should be divided into stages. After comprehending and solving the main masses, large color spots, you need to go on to clarify the shape, warmth, tone, materiality, and at the final stage, with a small brush, clarify all the nuances, achieve the expressiveness of all elements. "An abundance of light, a variety of reflexes, a great distance between landscape objects from the observer, a change in 
illumination and light-air environment and boundless space - all these are completely unusual and new conditions and opportunities for the artist to work from nature," as noted by K.M. Zubrilin. [4] During the period of work, you also need to pay attention to the techniques of writing. Many students, due to their inexperience, write subjects taking into account understanding, identification of this subject in practical life: carrots - orange, watermelon - green, trunk - brown, leaves - green. This means not only the object color. The object color in the environment can also be different, and the associative image of the object is modeled by the individual. Due to the lack of experience in painting among many students, this image is at the level of consciousness of the layman, and it is necessary that it be an element of the spatial environment, the structure of the surrounding world, light-tone influence and it must be modeled taking into account the specified parameters. The color of this object will depend on the source of illumination, luminosity, state, influence of other objects, the angle of view of the observer. "Numerous outdoor exercises allow future artists to develop professional visual acuity: linear and plane, spatial, light, coloristic". [4] Accordingly, to write out objects along the contour, to paint from top to bottom in one color - these are the few mistakes that inexperienced artists are subject to. "Since that time, many artists, resorting to the psychology of color, have enhanced the perception of the effects used in paintings on humans. After all, the mechanism of color perception, like the phenomenon of color itself, is not simple: it contains both an objective principle (light) and a subjective one (vision). In nature, color does not exist, it appears only at the moment of our perception, as our sensation. We all have the ability to perceive objects and phenomena. We strive to understand what we see". [5] Burovkina L.A. also points to this. "The painting classes reveal the basic patterns of perception of color, its properties, color issues, methods of working on a work of art. The knowledge gained in practical classes in the classroom, in the open air, is consolidated in the process of students' independent work". [6]

Working in the open air requires quick, correct decisions. The ability to choose the desired motive from the entire environment, to simulate the situation of spatial relationships, quantities and actions - semantic load, characterizes the student as a future professional, capable of operational actions, operational thinking, capable of capturing, grasping the momentary state of nature. Stendhal also noted: "Titian's knowledge of color consists in an infinite number of observations of the interaction of adjacent colors and their subtle differences, as well as in the ability to convey these differences. His trained eye distinguishes twenty different shades of yellow in a basket of oranges, leaving a clear memory in itself. "[7] Depending on the region, climatic zone, conditions in nature change very quickly. Imagine a spring day, the sun, clouds and it will become obvious that constant changes in the shape of clouds, their movement, changes in illumination, color, their shadows falling on a field, forest, river change the landscape in a matter of minutes due to the state of the composition, the emotional background, and in this diversity you need see, isolate exactly the motive that most fully reflects the nature of the landscape. In this regard, it is relevant to hold an open air at different times of the year and in different climatic zones. During the period of study, it is necessary to conduct plein airs, visiting different regions and countries in order to find the essential unchanging features characteristic of the plein air at any point in the world and to fix the features of landscape painting depending on the place of stay.

\section{Results}

The reform of educational processes requires a change in the structure of education, a conglomeration of synthesis of many sciences and activities. According to Yu.P. Zinchenko. "In the field of education, the theory of convergence is associated with overcoming the disciplinary boundaries traditionally formed in pedagogical thinking and 
scientific culture, disciplinary disunity and the search for new concepts and educational practices focused on integrative, interdisciplinary trends." [8]

Distance learning of painting in open air practice is possible only as a component of the educational process. "The main task of such training is to develop in students of pedagogical universities a holistic understanding of the synthesis of information technologies with general cultural processes in education, an understanding of the role of computer technologies in activities, the formation of information and graphic culture in parallel with the creative and research qualities of a person and the ability to professionally apply innovative technologies in educational process "- says M.Kh. Danashev. [9] It is impossible to exclude a mentor, teacher, leader from the learning process.

The process of teaching painting is complex in terms of the internal structure of the educational process, it is multifaceted and individual, more precisely. it is exclusive because each specific case is direct, takes into account the full range of psychological and intellectual components of the individual, the psychotype of the teacher and the system of educational tasks being implemented at the moment. A.A. Prischepa notes "The art of plein air is complex and multifaceted, especially when this aspect of creativity becomes not only an object of the artist's creative reincarnation, but also an educational and methodological base, ie. the artist acts as an artist-teacher, and his painting, drawing, made in open air conditions, are performed taking into account the development of visual literacy by students. Students need to directly observe not only the work of the master, but also receive practical recommendations, see the organization of plein-air activities, study the techniques of graphic and pictorial techniques, learn the rules for constructing a composition, the formation of plot, finding an artistic image, analyze the entire complexity of artistic, creative, educational and educational process ". [10] Nevertheless, distance learning is possible, and as the results of an experiment conducted during the current pandemic show, this is a special form of education that requires further research, the development of a special type of programs, methods, diagnostics, monitoring and, in general, a complete package of educational services, i.e. .to. it was said earlier that this is a special form of education that falls outside of traditional or individual learning. Diagnostics of the results of distance learning of painting students revealed in some cases difficulties in working with IT technologies. This is also indicated by A. M. Alenezi "It was found that students are far from always able to clearly identify their educational needs on their own and understand, without resorting to outside help, in a new arsenal of teaching aids, their adequate application and quality." [11] In the studies of Maidibor ON. says: "The understanding of the rules of the aerial perspective is facilitated by new innovative technologies embedded in computer graphics. One of the techniques is to enlarge the landscape photographs until the pixels appear, similar to the technique of oil painting. The boundaries and zones of change in color and light saturation are visible just along their clear contours. " [1] The student needs to prepare and equip with materials and equipment, provide his own plein-air practice with high-quality components, depending on the requirements of the curriculum. This is only a choice of material: gouache, watercolors, oils, pastels and many others, but also to ensure the safety of life in an open space. It should be borne in mind that the practice is associated with the summer season. "Only plein air painting makes it possible to understand how closely and firmly connected the world of nature and the world of man. And in order to feel and see this connection and harmony of the relationship between nature and man, constant practice and deep theoretical knowledge is needed, "as noted by KM Zubrilin. [4] Being in nature during the summer season requires a hotel complex of precautions, especially during a pandemic, which can contribute to a successful work result. Consequently, the distance learning environment requires a number of methodological recommendations. To correspond to the completeness, completeness of the learning process in the open air, we have identified several methodological segments: 
- protection of life safety, which was mentioned above;

- equipment;

- IT zone;

- mobile creativity;

- independent work;

- identification.

Prokhorov S.A. also indicates to us in his works: "It should be added that the proposed methodology for the development of artistic training by students in the design of an architectural environment from realistic painting to color-graphic interpretations of computer technologies as an artistic component meets modern requirements for the design of forms and objects, including advanced computer interactive and holographic design associated with architectural space. " [12]

For equipping with materials and equipment for plein-air practice, an indispensable condition is the artist's umbrella, which hides it from the sun's rays in the absence of its high-quality paint layer, and, accordingly, it is impossible to get a painting, you also need a sketchbook, a folding chair, closed shoes, outerwear, the presence of a headdress, disinfectant, drinking water, etc. depending on the specifics of the study assignment.

Distance learning is impossible without the Internet; therefore, it is necessary to have IT programs that provide communication with the head of the practice. Moreover, these programs should implement conferencing so that students can see the work of other students online and so that the leader controls the work of the entire group, which is dispersed across selected objects. Thus, the competence of the head of the practice is of particular importance, as noted by G.Z. Efimova. "One of the significant components of the ideal image of a university teacher are personal qualities, which, among other things, become an example for students in everyday life and professional activity" [13] Therefore, both students and the leader should be provided with high-quality gadgets, both stationary and mobile with the presence of cameras with high resolution in pixels and zoom. Accordingly, initially the teacher must have a high level of qualifications in the field of IT technologies. For the implementation of this task, refresher courses will help. As E. Burns points out. "The use of advanced training programs in the field of digital technologies ensures transparency and comparability of national and international educational programs, as well as contributes to the development of academic and professional mobility of VET teachers." [14]

To a sufficient extent, distance learning of painting in the open air is made up of independent work, tk. the process of writing an educational work is stretched out in time, its duration takes from 12-16 academic hours, respectively, the head of the practice cannot track the work process of 12 trainees online, one way or another you have to divide the work of students into certain stages for timing is created - time for carrying out one or another stage, after which the teacher corrects the student's work. The work process is complicated by the fact that the student, with a certain frequency, needs to photograph the selected object - the motive of a landscape in wildlife, his own study and send it to the head of the practice, who compares the nature with the study and corrects the student's work process in accordance with the violations committed.

Learning to paint in the open air is associated with the transfer of tone, basic and nuance color relations based on a system of perspective reduction in an open space. In the conditions of traditional education, this methodological aspect has a trivial solution, but in the conditions of distance learning, taking into account the fixation of the motives of the landscape and educational work with cameras, it becomes practically unrealizable. Different cameras, different gadgets with different resolutions of color cards, with different resolutions of monitors of stationary computers make it almost impossible to determine the original motive of the landscape, given that the light and shadow situation in the landscape 
changes during the day. It may seem that distance learning is not effective, but in the absence of the opportunity to resolve one didactic aspect, it becomes possible to implement another, no less important in teaching painting in the open air. This is the task of the warmth of a pictorial composition. Understanding the warmth of a painting is very important for the formation of professional competencies of a future specialist. And in this aspect, failures in the nuance palette of the transfer of color relations are allowed, since the warmth of the painting layer is preserved. Nevertheless, further improvement of computer technology should resolve this educational aspect as well.

In order to motivate students of art schools and students of art universities, as well as in order to successfully implement the project of distance learning in the field of fine arts of the State Budgetary Educational Institution of Education of the Republic of Uzbekistan "Steps of Success", the program "mobile tutor" is being implemented. On the basis of the aforementioned center, we have developed a painting training program in a pandemic. The master class was held using the system.

During the period of the experiment, a diagnosis of the creative level was carried out for the transfer of pictorial qualities among students-trainees. Conventionally, the period of practice was divided into 3 stages: the initial stage, when students were tested for the perception of color and light transmission, compositional construction. The group showed the presence of high, medium and low levels. At the middle stage, the pictorial qualities of the performed works of students increased in equal proportion. And only at the final stage, the quality results were demonstrated that sharply differ in the two groups (academic and distance). The data are presented in the table

Table 1. Monitoring the quality of painting. (academic group 90 people), [\%]

\begin{tabular}{|c|c|c|c|}
\hline level & I stage & II stage & III stage \\
\hline High level & 20 & 22 & 25 \\
\hline Average level & 65 & 65 & 65 \\
\hline Low level & 15 & 13 & 10 \\
\hline
\end{tabular}

Table 2. Painting quality monitoring (remote group of 30 people), [\%]

\begin{tabular}{|c|c|c|c|}
\hline level & I stage & II stage & III stage \\
\hline High level & 20 & 20 & 25 \\
\hline Average level & 65 & 65 & 60 \\
\hline Low level & 15 & 15 & 15 \\
\hline
\end{tabular}

\section{Discussion}

Distance learning in the field of art education synthesizes a lot of problems in pedagogy that require a comprehensive solution and simultaneous implementation in the educational process. Along with the problems of artistic training of students, according to Lomov S.P., Burovkina L.A., Zubrilin K.M., the formation of personal and professional qualities of students in acquiring the skills of painting and graphic techniques in the open air is associated with an understanding of color, tone, composition, plot. It should be borne in mind that this problem exists during the period of the reform of educational systems both at the international and domestic levels, and the proposed concept must be taken into account since the education of the 21 st century is based on the globalization of educational and methodological processes, as stated by Zinchenko. The personality of the student is integrated into the educational world structure, taking into account the identification of his personal qualities and the level of development of consciousness, as Alenezi points out in 
the current system of professional training, he is not self-sufficient, but requires participation, support of the teacher and also the personal qualities of the teacher must meet the previously prepared requirements, which Efimova notes. The importance of developing uniform international and national training programs for future specialists is relevant for many countries of the world - this is indicated by Burns. The presence of a single educational space allows you to build learning trajectories not only in the field of art education, but also to simulate the syncretic nature of educational programs. In addressing these issues, it is necessary to use the media space. The World Wide Web allows you to quickly respond to changing conditions in the educational environment.

\section{Conclusions}

Distance learning revealed a number of methodological aspects, revealed a connection between painting as an academic discipline and related sciences and arts of life safety, engineering, computer technology, programming, etc. Innovative technologies at the present stage provide distance learning in painting according to the main base of methodological requirements. To improve the process of remote teaching of painting in specific aspects, it is necessary to modernize and improve the IT software. The head of the practice, conducting diagnostics and assessment of educational work, needs to take into account that when many positive aspects appear in working with an electronic educational resource, new programs, information security, which, of course, affects the quality of education, there are programs on the Internet that make it possible to correct and to process the educational paintings of students, which gives them a qualitatively new level of performance, therefore, during the monitoring period, this process should be monitored, identified and prevented.

\section{References}

1. O.N. Maidibor, Alma mater, Bulletin of the higher school 3, 101-104 (2018).

2. S.P. Lomov, Painting (Textbook 3rd ed., Revised. and add. Agar, Moscow, 2008).

3. A.A. Prishchepa, History, theory and methodology of art education and upbringing: materials of the Mezhdunar in Proceedings of Scientific-practical conf., Krasnodar, Kuban State University, 2020.

4. K.M. Zubrilin, I.Yu. Rudnev, Science and school 6, 175-180 (2016).

5. N.N. Chugay, S.V. Kostromina, Izvestia of the Rostov State University of Civil Engineering 1 (19) (19), 291-294 (2015).

6. Stendhal, Life of Leonardo da Vinci. From the book "History of Painting in Italy (OLMA Media Group, Moscow, 2014).

7. Yu.P. Zinchenko, E.M. Dorozhkin, E.F. Zeer, The Education and science journal 22 (3), 11-35 (2020).

8. M.Kh. Danashev, Successes of modern science and education 12 (1), (2016).

9. A.A. Prishchepa, Formation of the artistic image in the open air by students-designers, The team of authors "Construction and Architecture - 2015". The current state and prospects for the development of environmental engineering systems, construction technologies, materials and quality in construction: materials of the International Scientific and Practical Conference, Rostov-on-Don Growth. state builds. un-t. 524 (2015)

10. A.M. Alenezi, The Education and science journal 22(4), 89-109(2020) 
11. S.A. Prokhorov, A.V. Shadurin, N.S. Prokhorov, Manuscript 13 (5), 199-203 (2020).

12. G.Z. Efimova, A.N. Sorokin, M.V. Gribovskiy, The Education and science journal 23 (1), 202-230 (2021).

13. E. Burns, E. Silvennoinen, V.A. Kopnov, D.E. Shchipanova, N. Papić-Blagojević, S. Tomašević, The Education and science journal 22 (9), 174-203 (2020). doi.org/10.17853/1994-5639-2020-9-174-203

14. H. Zaghloul, M. Rabeh, The Education and science journal 22 (1), 170-192 (2020). doi.org/10.17853/1994-5639-2020-1-170-192 